\title{
Short communication: The effects of morning compared with evening feed delivery in lactating dairy cows during the summer
}

\author{
M. Niu ${ }^{1}$ and K. J. Harvatine ${ }^{2}$ \\ Department of Animal Science, Penn State University, University Park 16802
}

\begin{abstract}
Delivering fresh feed in the evening is a management strategy sometimes used during periods of heat stress, but previous experiments have observed that night feeding increased feed intake during the $2 \mathrm{~h}$ after feeding and did not change intake during the overnight period. The objective of this study was to determine the effect of night feeding on daily rhythms of the dairy cow during the summer season. Twelve Holstein cows were used in a crossover design with 14-d periods. An automated system recorded the timing of feed intake over the last $7 \mathrm{~d}$ of each period. Treatments were ad libitum feeding with fresh feed delivery $1 \times / \mathrm{d}$ at $0830 \mathrm{~h}$ or $2030 \mathrm{~h}$. Milk yield and composition were not changed by treatment, but night feeding decreased the concentration of preformed fatty acids in milk fat. Night feeding decreased feed intake $1.7 \mathrm{~kg} / \mathrm{d}$, and decreased total-tract dry matter and neutral detergent fiber (NDF) digestibility by 0.7 and 0.8 percentage units, respectively. The amount of feed consumed in the first $2 \mathrm{~h}$ after feeding was $64 \%$ greater with night feeding, but intake did not differ between treatments during the night or early afternoon. A treatment by time of day interaction was observed for fecal NDF and indigestible NDF concentration and plasma glucose, insulin, and urea concentrations. Night feeding resulted in an increase in plasma insulin after feeding, which decreased plasma glucose. The daily rhythm of core body temperature was entrained by treatment, with the phase shifted and the amplitude decreased by night feeding indicating alteration of the central clock. In conclusion, feeding cows once per day in the evening during the summer caused a similar increase in feed intake and plasma insulin after feeding as previously observed during non-heat stress seasons. Night feeding also decreased intake and totaltract digestibility. The daily pattern of feed intake and
\end{abstract}

\footnotetext{
Received August 5, 2017.

Accepted September 17, 2017.

${ }^{1}$ Current address: Farmers Business Network, San Carlos, CA 94070.

${ }^{2}$ Corresponding author: kjh182@psu.edu
}

other behaviors should be considered before initiation of night feeding.

Key words: circadian, daily pattern, feeding behavior, night feeding

\section{Short Communication}

Total mixed rations are commonly fed ad libitum, but fresh feed is often only delivered once per day. Delivery of fresh feed in the evening, or night-feeding, is sometimes employed during periods of heat stress to provide fresh feed during the cooler part of the day with the expectation that cows will be more active during this period (Aharoni et al., 2005). Limited work has investigated the efficacy of night feeding, but Calamari et al. (2013) recently reported that average core body temperature was decreased $0.34^{\circ} \mathrm{C}$ and respiratory rate was decreased 6.2 breaths/min by evening feeding compared with morning feeding.

Circadian rhythms are 24-h repeating cycles that affect most physiological processes in the body. The dairy cow has a natural daily pattern of feed intake with high intake after fresh feed delivery and during the afternoon and early evening and lower intake during the overnight period (e.g., DeVries and von Keyserlingk, 2005; Rottman et al., 2015). This natural pattern appears to be a robust circadian rhythm that is maintained during evening feeding (Nikkhah et al., 2008; Niu et al., 2014). We recently compared feeding $1 \times / \mathrm{d}$ at 0830 or $2030 \mathrm{~h}$ and $2 \times / \mathrm{d}$ feeding at the same times and observed the daily pattern of feed intake and key plasma metabolites and metabolic hormones (Niu et al., 2014). However, the Latin square experiment was conducted during late winter in the absence of heat stress (February and March). The current experiment was conducted during late summer (August and September) at the Pennsylvania State University Dairy Production Research and Teaching Center to investigate the effect of night feeding on the daily pattern of feed intake during a warmer season (approved by the Penn State Institutional Animal Care and Use Committee). A temperature data logger recorded barn temperature over the day (HOBO Pendant Temp/Light, Onset Computer Corp., Bourne, 
MA). The highest daily temperature $25.7 \pm 1.21^{\circ} \mathrm{C}$ (mean $\pm \mathrm{SD}$ ) around $1600 \mathrm{~h}$ and the lowest daily temperature was $19.3 \pm 3.51^{\circ} \mathrm{C}$ (mean $\pm \mathrm{SD}$ ) around 0400 h. Twelve noncannulated multiparous Holstein cows $(2.8 \pm 0.27$ parities; $254 \pm 20.5$ DIM; mean \pm SD) were housed in a tiestall barn with rubber mats (Wingflex, Gummiwerk Kraigburg Elastik, Germany) and sawdust bedding and randomly assigned to treatment sequences in a crossover design with 14-d periods. The corn silagebased TMR contained $33.4 \%$ NDF, $18.4 \%$ starch, and 17.7\% CP [Supplemental Table S1; https://doi.org/10 $.3168 /$ jds.2017-13635; analyzed as described by Niu et al. (2014)]. Treatments were fed $1 \times / d$ at 0830 or 2030 h. A light-sensing data logger verified a consistent $18 \mathrm{~h}$ light and $6 \mathrm{~h}$ of dark schedule (dark $\sim 2300$ to $0500 \mathrm{~h}$ ).

Data were analyzed as described by Niu et al. (2017). Briefly, data observed across the day were analyzed using the MIXED procedure of SAS with repeated measures (version 9.3, SAS Institute Inc., Cary, NC). The model included the random effects of sequence, period, and cow nested in sequence and the fixed effect of treatment, time, and the interaction of treatment and time. The effect of treatment was tested at each time point. Time course data were also fit to a cosine function with a 24-h period for circadian rhythm analysis using the linear form of the cosine function in Proc Mixed. The preplanned contrast tested the differences in amplitude and acrophase (reported as time at peak). Parameters averaged over the day were analyzed with a reduced model that did not include the effect of time using JMP (version 9.4, SAS Institute Inc.). Significance was declared at $P<0.05$ and $P<0.10$ for main effects and interactions, respectively, and tendencies at $P<0.10$ and $P<0.15$, respectively.

Cows were milked twice daily at 0500 and $1700 \mathrm{~h}$ and milk yield determined by an integrated milk meter (AfiMilk; SAE Afikim, Israel) and analyzed as the average of d 12 to 14 of each period. Milk yield averaged $31.2 \mathrm{~kg} / \mathrm{d}$ and was not different between treatments (Table 1). Milk was also sampled at both milkings from d 12 to 14 of each period and analyzed for concentration of fat (filter B) and true protein by infrared spectroscopy (Dairy One Lab, State College, PA). Milk fat and protein concentration and yield was not different between treatments and both were above breed average ( $4.2 \%$ fat and $3.4 \%$ protein; Table 1 ). Milk fatty acid profile was determined by GC with a flame ionization detector at each milking on d 14 as described by Rico and Harvatine (2013) as modified by Niu et al. (2014). Intermediates of the normal and alternate biohydrogenation pathway (trans-10 C18:1 and trans-11 C18:1, respectively) were not different between treatments. Niu et al. (2014) also did not observe a change in milk yield or composition or trans fatty acids (FA) in cows producing $50 \mathrm{~kg} / \mathrm{d}$ of milk. However, in the current experiment, night feeding increased preformed (FA $>16$ C) 1.1 percentage points and decreased mixed source FA $(16 \mathrm{C}) 1.3$ percentage points, whereas de novo synthesized FA (FA $<16 \mathrm{C})$ were not changed. The decrease in preformed FA is opposite of classical dietinduced milk fat depression, which results in a larger decrease in de novo synthesized FA. As discussed below, plasma insulin was increased with night feeding and the decrease in preformed FA concentration is consistent with previous observations of decreased milk preformed FA during glucose and insulin infusion (reviewed by Harvatine et al., 2009).

Feed refusals were sampled before feeding from d 8 to 14 of each period. Daily DMI was decreased 1.7 $\mathrm{kg} / \mathrm{d}$ in night-fed cows (Table 1). Night feeding did not change DMI during the winter in Niu et al. (2014) when feeding a lower NDF diet $(29.7 \%)$ or during non-heat stress summer conditions (Manitoba, Canada; average $20.4^{\circ} \mathrm{C}$ and $68.1 \%$ humidity) in Nikkhah et al. (2008), who tested both high- and low-concentrate diets. In the current experiment, NDF digestibility was decreased by night feeding (discussed below) and in combination with the higher NDF level may have caused physical limitations of intake during some periods of the day.

Fecal samples were collected 6 times over the day and total-tract DM and NDF digestibility were determined using indigestible NDF (iNDF) as a flow marker as described by Niu et al. (2017). Total-tract DM digestibility of cows fed at night was decreased by 0.7 percentage points and NDF digestibility was decreased 0.8 percentage points. Digestibility has not been well studied during night feeding, but Niu et al. (2014) did report a numerical decrease in total-tract NDF digestibility. The decrease in digestibility may be due to the large amount of feed consumed after feeding in the night-fed group discussed below. This "slug-feeding" is expected to increase rumen acid load during the late evening and may inhibit fibrolytic bacteria. It is important to note that this rapid intake occurs after a moderate rate of feed intake during the afternoon, compared with morning-fed cows who have a much lower intake rate over the $8 \mathrm{~h}$ before feeding (overnight period). Thus, rumen starch concentration and amylolytic capacity are expected to be higher before feeding in night-fed cows, resulting in a larger effect of rapid feed intake on the rumen environment.

Fecal NDF and iNDF concentration are known to follow a daily pattern that is modified by feeding time (Niu et al., 2014, 2017). Fecal NDF concentration was 2.2 percentage units higher in morning-fed cows at 0700 and was 2.4 percentage units lower than eve- 
Table 1. Effect of feeding time on milk production and composition and fatty acid (FA) profile, DMI, and total-tract (TT) digestibility of cows fed a TMR once per day during the summer

\begin{tabular}{|c|c|c|c|c|}
\hline \multirow[b]{2}{*}{ Item } & \multicolumn{2}{|c|}{ Treatment mean ${ }^{1}$} & \multirow[b]{2}{*}{$\mathrm{SE}$} & \multirow[b]{2}{*}{$P$-value ${ }^{2}$} \\
\hline & $\mathrm{AM}$ & $\mathrm{PM}$ & & \\
\hline \multicolumn{5}{|l|}{ Yield, $\mathrm{kg} / \mathrm{d}$} \\
\hline Milk & 31.2 & 31.2 & 1.60 & 0.91 \\
\hline Fat & 1.29 & 1.30 & 0.083 & 0.61 \\
\hline Protein & 1.06 & 1.06 & 0.050 & 0.85 \\
\hline \multicolumn{5}{|l|}{ Milk composition, \% } \\
\hline Fat & 4.17 & 4.21 & 0.242 & 0.31 \\
\hline Protein & 3.42 & 3.44 & 0.164 & 0.71 \\
\hline \multicolumn{5}{|l|}{ Milk FA, $\%$ of FA } \\
\hline trans-10 C18:1 & 0.37 & 0.35 & 0.022 & 0.11 \\
\hline trans-11 C18:1 & 1.10 & 1.08 & 0.092 & 0.53 \\
\hline cis-9,trans-11 CLA & 0.60 & 0.58 & 0.027 & 0.36 \\
\hline trans-10,cis-12 CLA & $\mathrm{ND}^{3}$ & ND & - & - \\
\hline$\Sigma \mathrm{FA}<16 \mathrm{C}^{4}$ & 25.1 & 25.6 & 0.55 & 0.12 \\
\hline$\Sigma 16 \mathrm{C}^{4}$ & 38.9 & 37.6 & 0.54 & 0.03 \\
\hline$\Sigma \mathrm{FA}>16 \mathrm{C}^{4}$ & 29.2 & 30.3 & 0.65 & 0.03 \\
\hline $\mathrm{DMI}, \mathrm{kg} / \mathrm{d}$ & 27.0 & 25.3 & 1.33 & $<0.01$ \\
\hline \multicolumn{5}{|l|}{ TT digestibility, \% } \\
\hline DM & 65.6 & 64.9 & 0.27 & $<0.01$ \\
\hline $\mathrm{NDF}$ & 43.8 & 43.0 & 0.70 & 0.02 \\
\hline
\end{tabular}

${ }^{1}$ Least squares means. $\mathrm{AM}=$ feeding once a day at $0830 \mathrm{~h} ; \mathrm{PM}=$ feeding once a day at $2030 \mathrm{~h}$. All times are Eastern Standard Time.

${ }^{2}$ Effect of treatment.

${ }^{3} \mathrm{ND}=$ below the level of detection.

${ }^{4}$ Fatty acids $<16 \mathrm{C}$ originate from the mammary gland (C15:0 is not included); FA $>16 \mathrm{C}$ originate from plasma; 16 C FA originate from both sources.

ning fed cows at $1600 \mathrm{~h}$ (Figure 1). Fecal NDF and iNDF concentration fit a cosine with a 24 -h period in both treatments (Supplemental Table S2; https://doi .org/10.3168/jds.2017-13635). Fecal NDF and iNDF were phase shifted 5.5 and $9 \mathrm{~h}$ with night feeding and decreased their amplitudes 0.23 and 0.71 percentage units, respectively. The phase shift was similar to that reported by Niu et al. (2014) during the winter, but the effect on the amplitude was the opposite.

Nine cows were housed in stalls equipped with a feed intake observation system using feed tubs hanging from load cells to observe the daily pattern of intake and meal parameters as described by Niu et al. (2017; Figure 1). Treatments did not differ in the rate of intake during the night (0000 to $0600 \mathrm{~h}$ ) and mid-day (1000 to 1600 h). Both groups increased intake after feeding, with morning-fed cows averaging $8.6 \%$ of daily intake per $\mathrm{h}$ from 0800 to $1000 \mathrm{~h}$ and evening fed cows averaging $14.1 \%$ of daily intake per h from 2000 to $2200 \mathrm{~h}$. Previous night feeding experiments observed approximately a $50 \%$ greater rate of feed intake after night feeding compared with morning feeding (Nikkhah et al., 2008; Niu et al., 2014). The morning-fed cows were also 1.9 percentage units higher in feed intake from 1600 to 1800 $\mathrm{h}$, before the evening feeding. It is noteworthy that, similar to previous work, the rate of feed intake did not differ between night-fed and morning-fed treatments during the night and early afternoon. In the current experiment, rate of intake in both treatments was only slightly higher during the afternoon compared with the night, whereas other experiments observed more than a 2-fold difference (Niu et al., 2014; Rottman et al., 2015; Ying et al., 2017). The rate of feed intake over the day fit a cosine function with a 24 -h period in both treatments. Night feeding shifted the phase of the daily rhythm ahead almost $3 \mathrm{~h}$ and decreased the amplitude 0.67 percentage points per hour (Supplemental Table S2; https://doi.org/10.3168/jds.2017-13635), similar to Niu et al. (2014). No effect was observed of treatment on meal number, meal size, or other meal parameters (Supplemental Table S3; https://doi.org/10.3168/jds .2017-13635).

Blood samples were collected on d 12 to 14 of each period (0300, 0700, 1100, 1500, 1900, and $2300 \mathrm{~h}$ ) and analyzed for insulin, glucose, BUN, and nonesterified fatty acids (NEFA) as previously described (Niu et al., 2017; Figure 2). Night feeding increased plasma insulin $98 \%$ at $2300 \mathrm{~h}$ and $25 \%$ at $0300 \mathrm{~h}$ and decreased insulin $28 \%$ at $1500 \mathrm{~h}$ and $56 \%$ at $1800 \mathrm{~h}$. This is expected due to the very high rate of intake after feeding in night-fed cows. Plasma insulin fit a cosine with a 24-h period in both treatments and night feeding phase delayed the rhythm $4 \mathrm{~h}$ and increased the amplitude from 2.30 to $2.87 \mu \mathrm{IU} / \mathrm{mL}$. Plasma glucose concentra- 

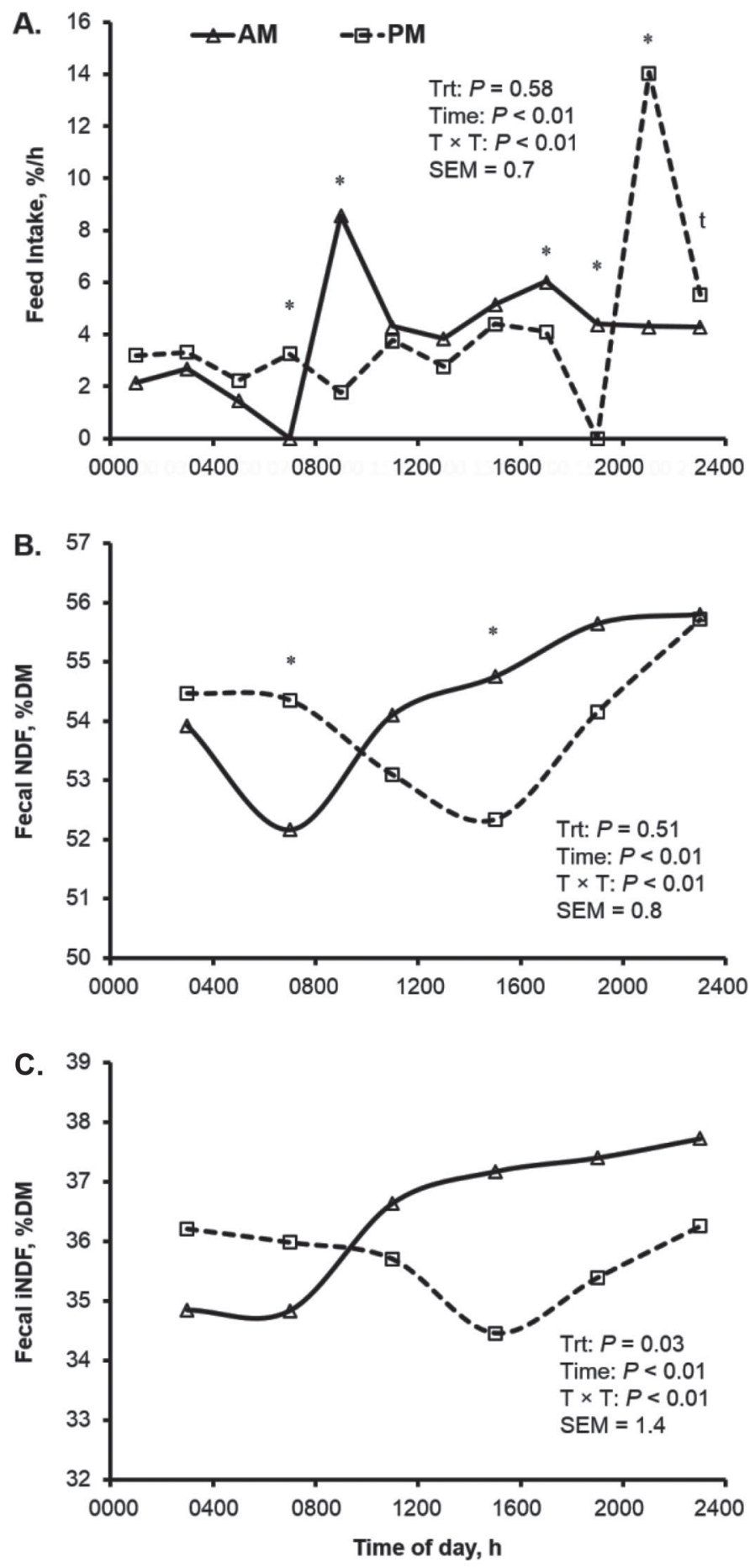

Figure 1. Effect of feeding time on the daily pattern of feed intake and fecal NDF and indigestible NDF (iNDF) concentration. Cows were fed the same TMR once a day at $0830 \mathrm{~h}$ (AM) or $2030 \mathrm{~h}(\mathrm{PM})$ during the summer. Effect of treatment (Trt), time, and their interaction $(\mathrm{T} \times \mathrm{T})$ is shown. Differences between treatment at each time point are shown $\left({ }^{*} P<0.05\right.$ and $\left.{ }^{\mathrm{t}} P<0.10\right)$. tion was increased in night-fed cows by $3.7 \mathrm{mg} / \mathrm{dL}$ at $1100 \mathrm{~h}$ and was decreased $5.9 \mathrm{mg} / \mathrm{dL}$ at $2300 \mathrm{~h}$. Plasma NEFA was increased in night-fed cows at 0300 and 1900 $\mathrm{h}$ and plasma BUN was increased over $2 \mathrm{mg} / \mathrm{dL}$ at $1100 \mathrm{~h}$. The increase in insulin and decrease in plasma glucose after feeding in the night-fed cows is similar to previous experiments (Nikkhah et al., 2008; Niu et al., 2014), which also reported decreased plasma NEFA through part of the night. Plasma NEFA decreased after feeding in night-fed cows, but was not different from morning-fed in the current experiment. This may be due to the lower production level of the cows in the current experiment. Last, plasma BUN was increased in morning-fed cows at $1100 \mathrm{~h}$, which followed the high rate of feed intake after feeding. Interestingly, BUN was not increased following the very high rate of feed intake after feeding in night-fed cows. Nikkhah et al. (2008) observed that BUN increased after morning and night feeding in cows fed a low-concentrate diet, but after night feeding in cows fed a high-concentrate diet. Interestingly, Niu et al. (2014) observed increased BUN after night feeding when feeding a lower NDF diet than that fed in the current experiment and other factors, such as production level, may interact.

Core body temperature was recorded every $10 \mathrm{~min}$ from d 8 to 14 of each period using an intra-vaginal temperature probe (iBCod; Alpha Mach Inc., MontSt.-Hilaire, QC, Canada) as previously described (Niu et al., 2014). The phase of the daily rhythm of body temperature was advanced from 2240 to $1849 \mathrm{~h}$ and the amplitude was decreased (Supplemental Table S2 and Supplemental Figure S1; https://doi.org/10.3168/jds .2017-13635). We had previously observed a decrease in the amplitude of body temperature during night feeding, but the phase was delayed (Niu et al., 2014). The modification of the rhythm of core body temperature indicates modification of the central biological clock, which is normally difficult with treatments other than lighting.

The effect of night feeding is consistent between warmer and cooler periods of the day and across locations and diet types in the literature. Night feeding results in higher feed intake in the $2 \mathrm{~h}$ after feed delivery compared with morning feeding, but has little effect on the low-intake period during the overnight period and high intake period during the afternoon. This rapid feed consumption in the evening has the potential to create SARA and increases plasma insulin, which decreases plasma glucose and NEFA and may direct nutrients away from the mammary gland. Therefore, care should be taken in establishment of night feeding strategies, although research during extreme heat stress conditions is needed. 

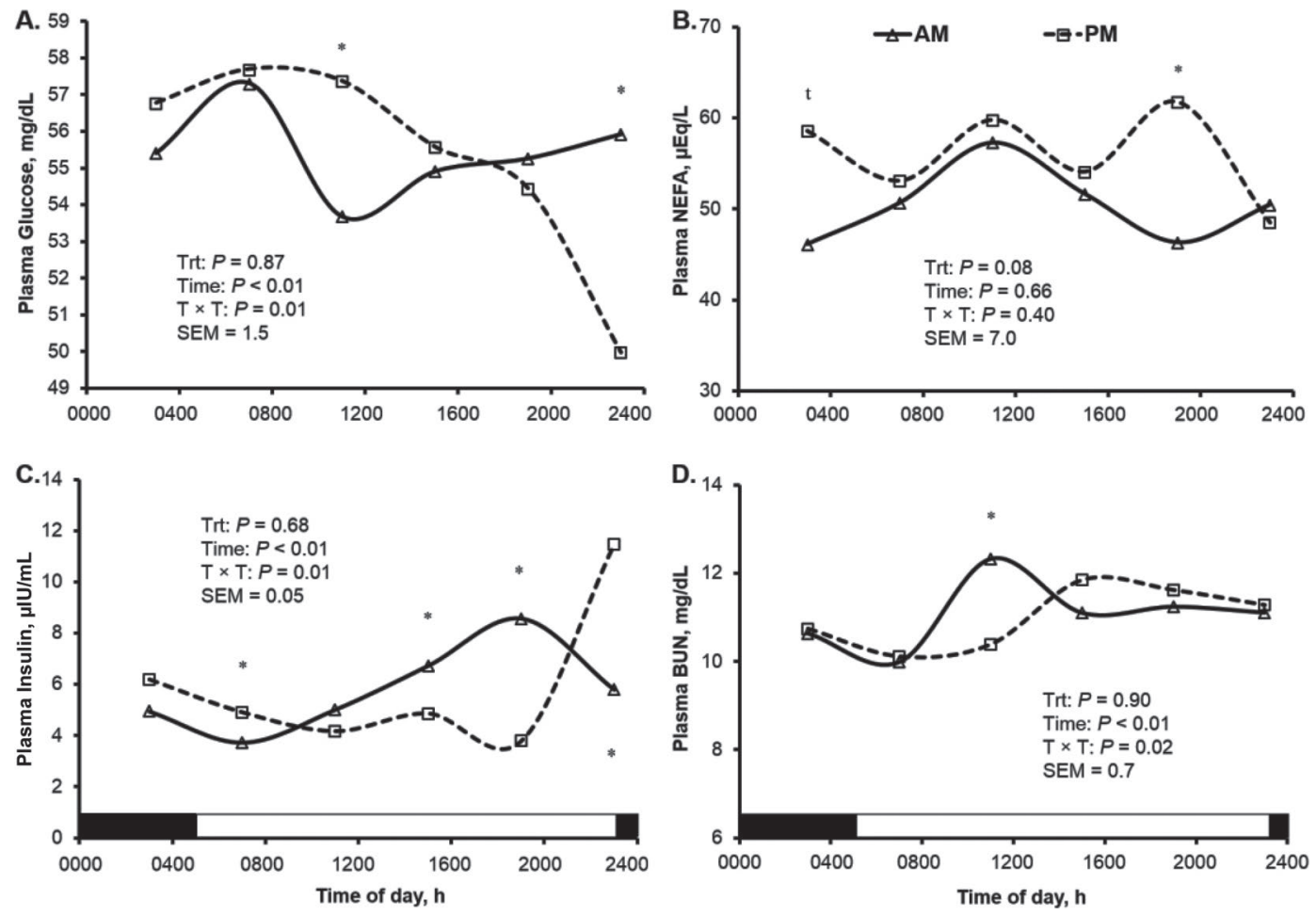

Figure 2. Effect of feeding time on the daily pattern of plasma glucose (A), nonesterified fatty acids (NEFA; B), insulin (C), and BUN (D). Cows were fed the same TMR once a day at $0830 \mathrm{~h}(\mathrm{AM})$ or $2030 \mathrm{~h}(\mathrm{PM})$ during the summer. Effect of treatment (Trt), time, and their interaction $(\mathrm{T} \times \mathrm{T})$ is shown. Differences between treatment at each time point are shown $\left({ }^{*} P<0.05\right.$ and $\left.{ }^{\mathrm{t}} P<0.10\right)$.

\section{ACKNOWLEDGMENTS}

The authors gratefully acknowledge the technical assistance of Yun (Jackie) Ying, Andrew Clarke, Jared Risser, Daniel E. Rico, Liying Ma, Kan Zhou, and Natalie Urrutia (Penn State University, University Park). Gratitude is also expressed to the Pennsylvania State University Dairy Cattle Research and Education Center. Research supported in part by USDA Special Grant 2009-34281-20116 (principal investigator Harvatine) and Penn State University.

\section{REFERENCES}

Aharoni, Y., A. Brosh, and Y. Harari. 2005. Night feeding for highyielding dairy cows in hot weather: Effects on intake, milk yield and energy expenditure. Livest. Prod. Sci. 92:207-219.

Calamari, L., F. Petrera, L. Stefanini, and F. Abeni. 2013. Effects of different feeding time and frequency on metabolic conditions and milk production in heat-stressed dairy cows. Int. J. Biometeorol. $57: 785-796$.

DeVries, T. J., and M. A. von Keyserlingk. 2005. Time of feed delivery affects the feeding and lying patterns of dairy cows. J. Dairy Sci. $88: 625-631$.
Harvatine, K. J., Y. R. Boisclair, and D. E. Bauman. 2009. Recent advances in the regulation of milk fat synthesis. Animal 3:40-54.

Nikkhah, A., C. J. Furedi, A. D. Kennedy, G. H. Crow, and J. C. Plaizier. 2008. Effects of feed delivery time on feed intake, milk production, and blood metabolites of dairy cows. J. Dairy Sci. 91:4249-4260.

Niu, M., Y. Ying, P. A. Bartell, and K. J. Harvatine. 2014. The effects of feeding time on milk production, total-tract digestibility, and daily rhythms of feeding behavior and plasma metabolites and hormones in dairy cows. J. Dairy Sci. 97:7764-7776.

Niu, M., Y. Ying, P. A. Bartell, and K. J. Harvatine. 2017. The effects of feeding rations that differ in fiber and fermentable starch within a day on milk production and the daily rhythm of feed intake and plasma hormones and metabolites in dairy cows. J. Dairy Sci. 100:187-198.

Rico, D. E., and K. J. Harvatine. 2013. Induction of and recovery from milk fat depression occurs progressively in dairy cows switched between diets that differ in fiber and oil concentration. J. Dairy Sci. 96:6621-6630.

Rottman, L. W., Y. Ying, K. Zhou, P. A. Bartell, and K. J. Harvatine. 2015. The effects of feeding rations that differ in neutral detergent fiber and starch concentration within a day on production, feeding behavior, total-tract digestibility, and plasma metabolites and hormones in dairy cows. J. Dairy Sci. 98:4673-4684.

Ying, Y., M. Niu, A. R. Clarke, and K. J. Harvatine. 2017. Short communication: Effect of a citrus extract in lactating dairy cows. J. Dairy Sci. 100:5468-5471. 